\title{
Histological effects of chronic sodium fluoride toxicity on some reproductive organs of male and female adult albino rats
}

\author{
H.B. Al-Sabaawy ${ }^{1(D)}$ and B.I. Al-Kaisie ${ }^{2}$ \\ ${ }^{1}$ Department of Pathology and Poultry Diseases, Collage of Veterinary Medicine, University of Mosul, Mosul, ${ }^{2}$ Department \\ of Pathology and Poultry Diseases, Collage of Veterinary Medicine, University of Baghdad, Baghdad, Iraq
}

\begin{tabular}{l} 
Article information \\
\hline Article history: \\
Received August 5, 2020 \\
Accepted September 16, 2020 \\
Available online October 1,2021 \\
\hline Keywords: \\
Sodium fluoride \\
Ovary \\
Testis \\
Histopathology \\
Chronic toxicity \\
\hline Correspondence: \\
H.B. Al-Sabaawy \\
hadeelbasim2006@gmail.com
\end{tabular}

DOI: $10.33899 /$ ijvs.2020.127896.1540, (CAuthors, 2021, College of Veterinary Medicine, University of
This is an open access article under the CC BY 4.0 license (http://creativecommons.org/licenses/by/4.0/).

\section{Introduction}

Fluoride is a natural element existing in the environment, prolonged exposure to fluoride $(\mathrm{F})$ in air, soil and water, resulting in accumulation of these ions in the body by forming salts, mainly in the bones so that fluoride level above 3-6 mg/L may lead to skeletal fluorosis and in teeth, the level above $1.5 \mathrm{mg} / \mathrm{L}$ lead to dental fluorosis in both human beings and domestic animals $(1,2)$. Fluoride has both useful and mischievous effects on public health; several studies indicate that fluoride in low concentration is fundamental for both man and animals especially for growth and development of teeth and bones (3) chronic exposure to fluoride have disruptive effects on various tissues of body like apoptosis, neurological disorder, gastrointestinal disturbances and reproductive system dysfunctions, hemorrhage and cardiac arrest $(1,4)$. Multiple investigations refer to a relationship between long-dated fluoride exposure and impairment of fertility thus, various experimental on mice, rabbit, Guinea big and rats refers to adverse effects of sodium fluoride on the reproductive function of it $(5,6)$ many researchers refer to modification in histological structures, reproductive hormone changes, fertility (7) and changes in organ body weight; the deleterious effects of sodium fluoride can be reduced by using different materials such as pomegranate seed oil (8), as well as the toxic effect of sodium nitrate can be reduced by ascorbic acid (9).

Therefore, the current work aimed to study the toxic effects of sodium fluoride on the male and female gentile system that exposed to different concentration of it. 


\section{Materials and methods}

\section{Animals housing}

Animals numbers for this experimental study is 36 adult's male and female albino rats weighing 180-200 gm. These animals were adopted in the animals housing of Collage of Veterinary Medicine at the University of Mosul, it divided randomly into six groups (Table 1). All treated groups were providing with these materials for 90 days.
Animals were housed under strict care, hygienic condition and ventilation with alight dark 12:12 cycle under standard temperature $24 \pm 26^{\circ} \mathrm{C}$ and the whole body weight of these animals was checked at three stages during the experimental period at the end of these experimental animals were sacrificed.

The male and female gonads were excised, and weighed and all sample were processed for histopathological examinations.

Table 1: Experimental protocol

\begin{tabular}{lccc}
\hline Groups & Treatment & Duration of exposure & Number of animals \\
\hline Control male & water tap & 90 days & 6 male \\
Control female & water tape & 90 days & 6 female \\
$150 \mathrm{ppm}$ male & fluoridated water & 90 days & 6 male \\
$150 \mathrm{ppm}$ female & fluoridated water & 90 days & 6 female \\
$300 \mathrm{ppm}$ male & fluoridated water & 90 days & 6 male \\
$300 \mathrm{ppm}$ female & fluoridated water & 90 days & 6 female \\
\hline
\end{tabular}

\section{Histopathological analysis}

Dissected tissue of testes was fixed in Bouin's solutions for $24 \mathrm{hrs}$. At the same time, the rest organs fixative in $10 \%$ of neutral buffer formalin and processed by the traditional way (concatenation of alcohol dilution for dehydration, cleared up by xylene, blocked in the wax of paraffin and the thickness of section is 3-4 $\mathrm{nm}$ which were sliced by using the microtome and stained by Hematoxylin and Eosin (H\&E) according to (10) and finally examined under the light microscope and the histological changes were visualized by using a digital camera and magnified to the required size.

\section{Statistical analysis}

To determine the toxic effects of sodium fluoride on animal's body, all collected data were analyzed by using one-way ANOVA and the moral differences for all tests are determined at $\mathrm{P}<0.05$ (11).

\section{Results}

\section{The relative weight of the male genitalia}

The treatment with sodium fluoride resulted in a significant decrease in testicular weight in the treated groups compared to the control group. The results showed a significant decrease in body weight, head, and epididymis tail in all treatments compared to the control group. Treatment of adult male rats with sodium fluoride caused a significant decrease in prostate weight in the treated groups compared to the control group. A significant decrease was observed in the weight of seminal vesicles of male rats treated with sodium fluoride compared to the control group (Table 2).

\section{The relative weight of the female genitalia}

The results of the present study showed that there was a significant decrease in the weight of female genital organs and all transactions compared to the control group as shown in the (Table 3), The treatment groups did not show a significant difference between them.

\section{Effects of sodium fluoride on the histological structure of male and female rats}

In control groups, the normal histology of ovary was (Figure 1), late tertiary follicle (preovulatory follicle) in addition to developing and growing of primordial follicles (Figures 2 and 3) which associated with theca luteal cell, tunica albuginea and epithelium of ovarian surfaces.

The figure 4 showed antral follicle (late tertiary follicle) in addition to primordial follicles. While figure 5 showed secondary follicles with different stage of developing.

Table 2: The effects of sub-lethal concentration of sodium fluoride on male genitalia organs weight

\begin{tabular}{lccc}
\hline \multirow{2}{*}{ Organs } & \multicolumn{3}{c}{ Mean \pm SE $(\mathrm{n}=6)$} \\
\cline { 2 - 4 } & Control & $150 \mathrm{ppm}$ & $300 \mathrm{ppm}$ \\
\hline Testis & $539.00017 \pm 15.00183^{\mathbf{a}}$ & $400.09850 \pm 19.739748^{\mathbf{b}}$ & $329.87200 \pm 10.798784^{\mathbf{c}}$ \\
Prostates & $406.44100 \pm 13.381972^{\mathbf{a}}$ & $339.60300 \pm 13.732154^{\mathbf{b}}$ & $254.35150 \pm 4.016649^{\mathbf{c}}$ \\
Seminal vesicles & $440.93000 \pm 12.618307^{\mathbf{a}}$ & $359.73433 \pm 12.220198^{\mathbf{b}}$ & $379.16650 \pm 1.863315^{\mathbf{b}}$ \\
Head of epididymis & $98.60233 \pm 1.354218^{\mathbf{a}}$ & $87.7560 \pm 1.485420^{\mathbf{b}}$ & $88.14767 \pm 1.492998^{\mathbf{b}}$ \\
Tail of epididymis & $109.40750 \pm 1.767612^{\mathbf{a}}$ & $85.72583 \pm 3.156051^{\mathbf{b}}$ & $89.62900 \pm 1.325094^{\mathbf{b}}$ \\
\hline
\end{tabular}

Horizontally different letters mean that there is a significant difference between the groups at $\mathrm{P}<0.05$. 
Table 3: The effects of sub-lethal concentration of sodium fluoride on female gentile organs weight

\begin{tabular}{lccc}
\hline \multirow{2}{*}{ Organs } & \multicolumn{3}{c}{ Mean \pm SE $(\mathrm{n}=6)$} \\
\cline { 2 - 4 } & Control & $150 \mathrm{ppm}$ & $300 \mathrm{ppm}$ \\
\hline Ovary & $30.57983 \pm 0.956699^{\mathbf{a}}$ & $24.49367 \pm 1.803669^{\mathbf{b}}$ & $23.37150 \pm 2.779209^{\mathbf{b}}$ \\
Horn of the uterus & $360.26533 \pm 7.0528504^{\mathbf{a}}$ & $226.47100 \pm 25.5573^{\mathbf{b}}$ & $214.99733 \pm 9.008086^{\mathbf{b}}$ \\
\hline
\end{tabular}

Horizontally different letters mean that there is a significant difference between the groups at $\mathrm{P}<0.05$.

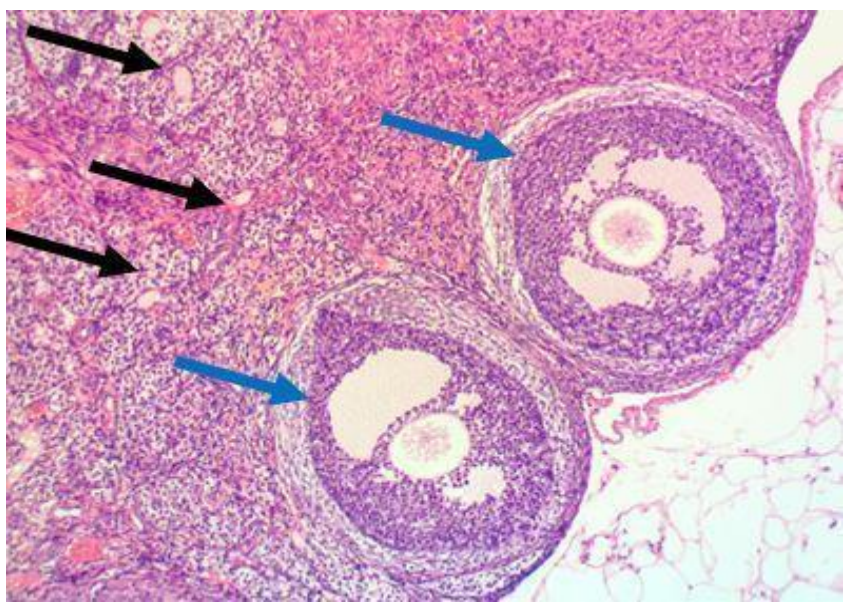

Figure 1: Control group, Ovary, Normal composition of ovarian tissue, many primordial follicles (arrow) with two antral follicles (mature preovulatory follicle (blue arrows) (H\&E, 10x).

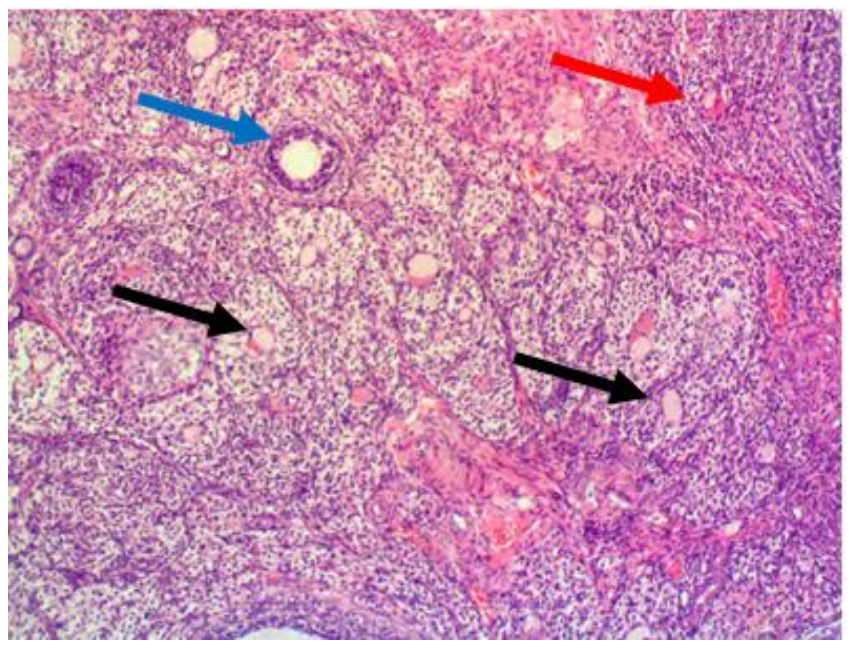

Figure 2: Control group, Ovary Normal composition of ovarian tissue showing developing and growing follicles included primordial follicles (arrow), primary follicles (arrow). (H\&E, 10x).

The figure 6 showed thinking in tunica albuginea as well as there is deposition of eosinophilic materials with many primordial.

In group administrated with $300 \mathrm{ppm}$ of $\mathrm{NaF}$ showed multiple ovulation with one atretic follicle (Figure 7), as well multi-layer primary follicles are present (Figure 8). Massive vacuolar degeneration in the cell of theca extern (Figure 9), increase in the thickness of tunica albuginea (Figure 10). congestion of blood vessels and vacuolar degeneration in luteal cell (Figure 11).

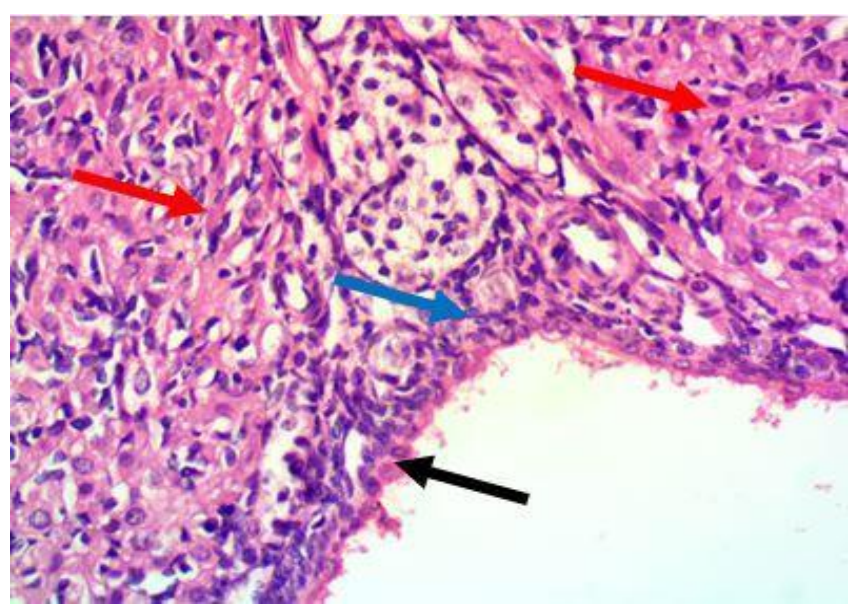

Figure 3: Control group, Ovary, Normal composition of ovarian tissue showing ovarian surface epithelium (arrow), tunica albuginea (arrow) and theca luteal cells (arrow) (H\&E, 400x).

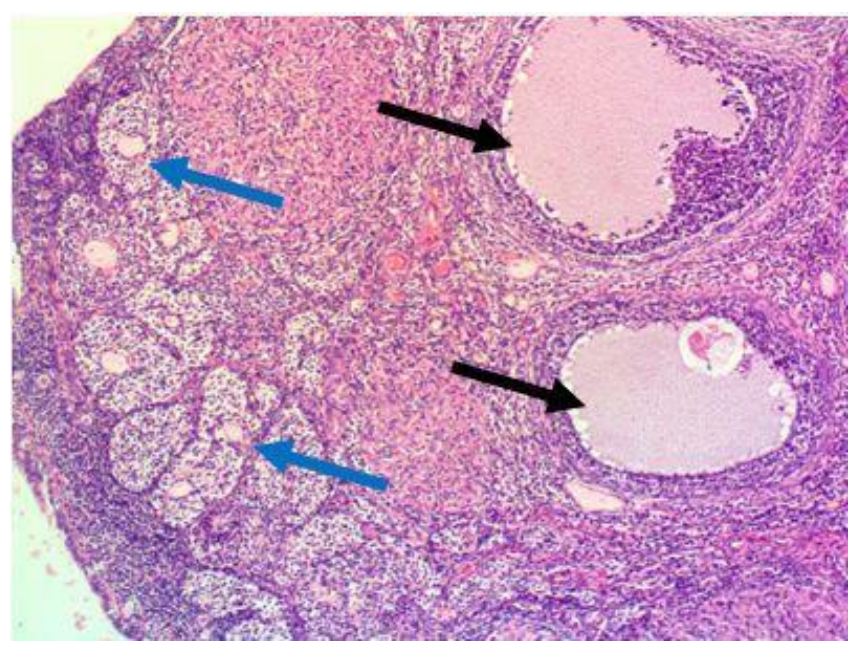

Figure 4: 150 PPM group. Ovary. Showing two antral follicles (arrow) with multiple secondary follicles (arrow). H\&E, 100x. 


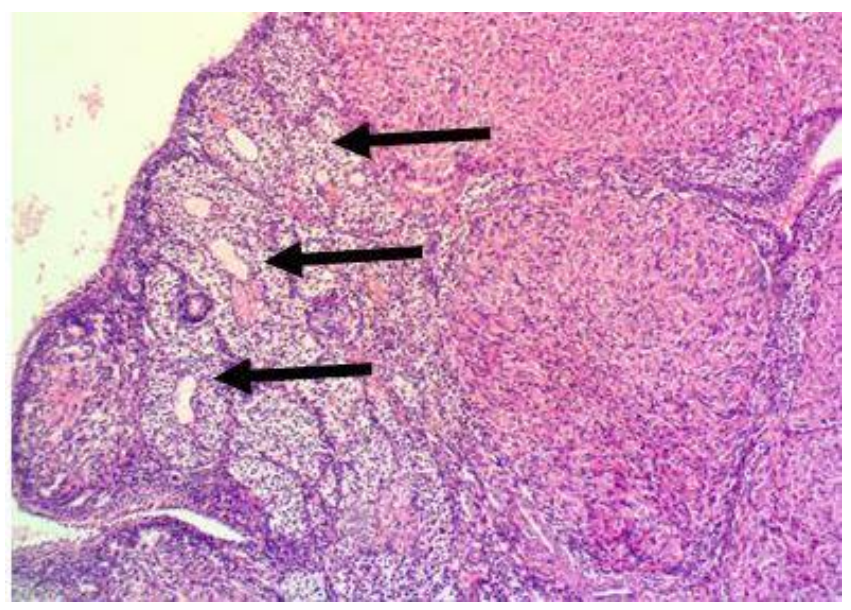

Figure 5: 150 PPM group. Ovary. Showing secondary follicles at a different stage of developing (arrow). H\&E, 100x.

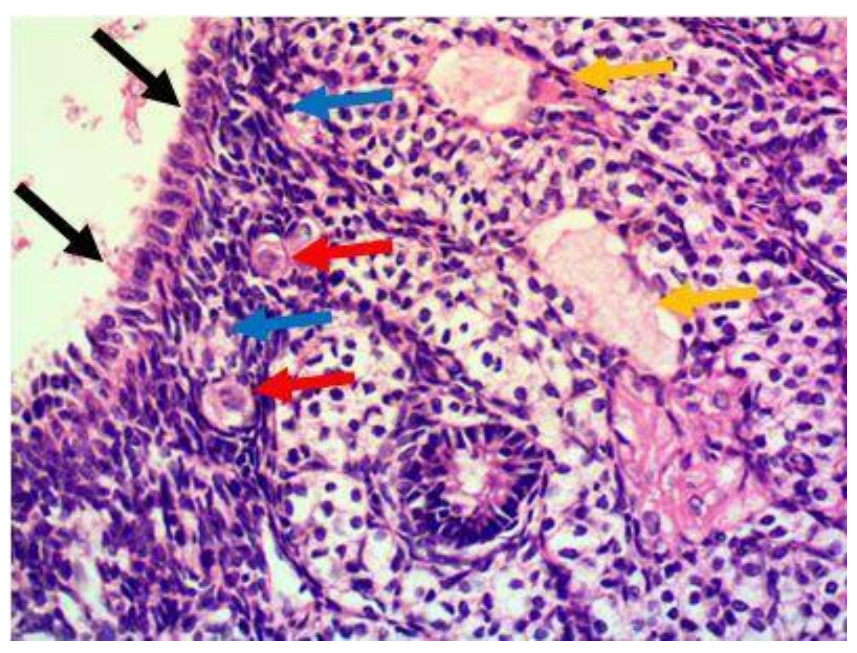

Figure 6: 150 PPM group. Ovary. Showing ovarian surface epithelium (arrow), thickening in tunica albuginea (arrow), many primordial follicles (arrow), deposition of eosinophilic materials (arrow). H\&E, 400x.

The control groups of male rats show the typical composition of seminal tubules with the complete stage of spermatogenesis, Leydig cell with supplying of blood (Figures 12 and 13). In $150 \mathrm{ppm}$ groups the testes organs show multinucleated spermatid with amorphous eosinophilic material in the interstitial tissue with degenerative cell in the stage of spermatid cell (Figures 14 and 15). While in 300 ppm groups showed massive coagulative necrosis which appears as debris with complete absence of spermatozoa (Figure 16), as well as there is a deposition of amorphous eosinophilic material and thickening in tunica vaginalis (Figure 17). The figure 18 showed increase in the thickness of tunica vaginalis in addition to coagulative necrosis in the endothelial cell of seminal tubules.

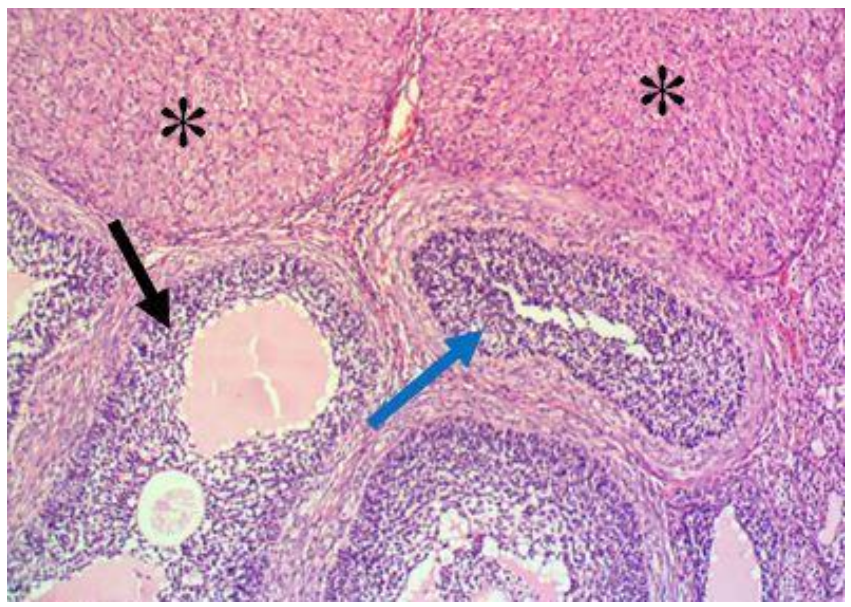

Figure 7: 300 PPM group Ovary. Case of multi ovulation with atrial follicles (arrow) and atretic follicle (arrow) with two distinct corpus luteum (star). H\&E, 100x.

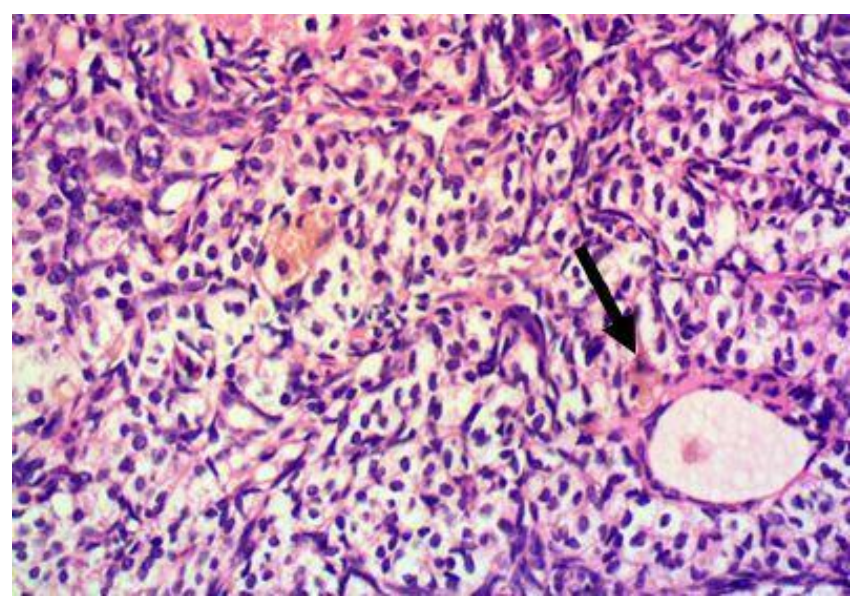

Figure 8: 300 PPM group. Ovary. Showing the presence of multilayer layer follicle (arrow). H\&E, 400x.

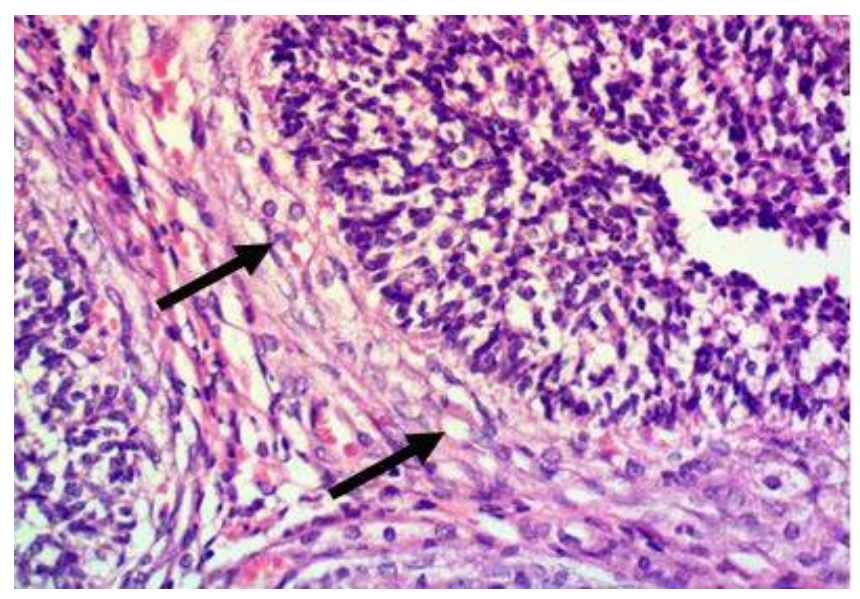

Figure 9: 300 PPM group. Ovary. massive vacuolar degeneration in theca externa cells (arrow). H\&E, 400x. 


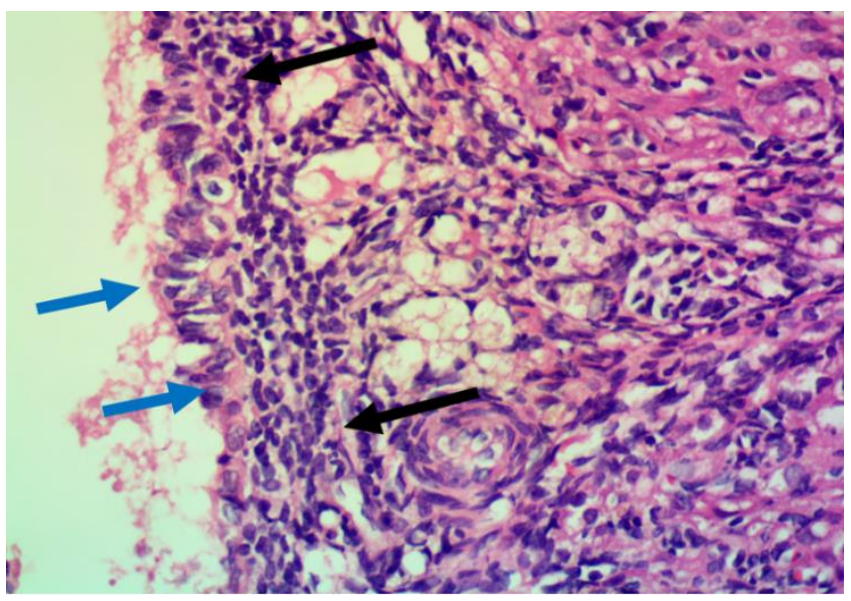

Figure 10: 300 PPM group. Ovary. Increase in thickness of tunica albuginea (arrow), vaculation (arrow) H\&E, 400x.

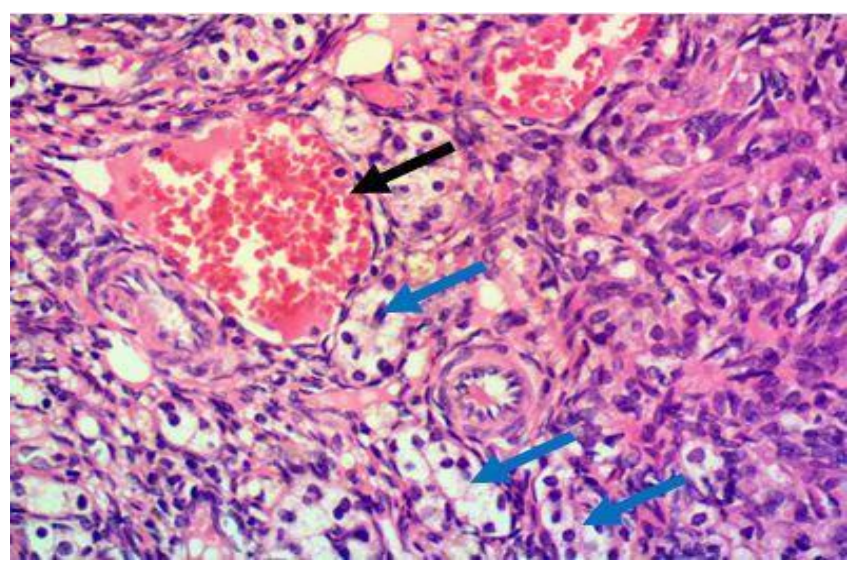

Figure 11: 300 PPM group. Ovary. Showed the congestion in the blood vessels (arrow), with presence of vacuolar degeneration in luteal cells in the ovary context (arrow). H\&E. 400X.

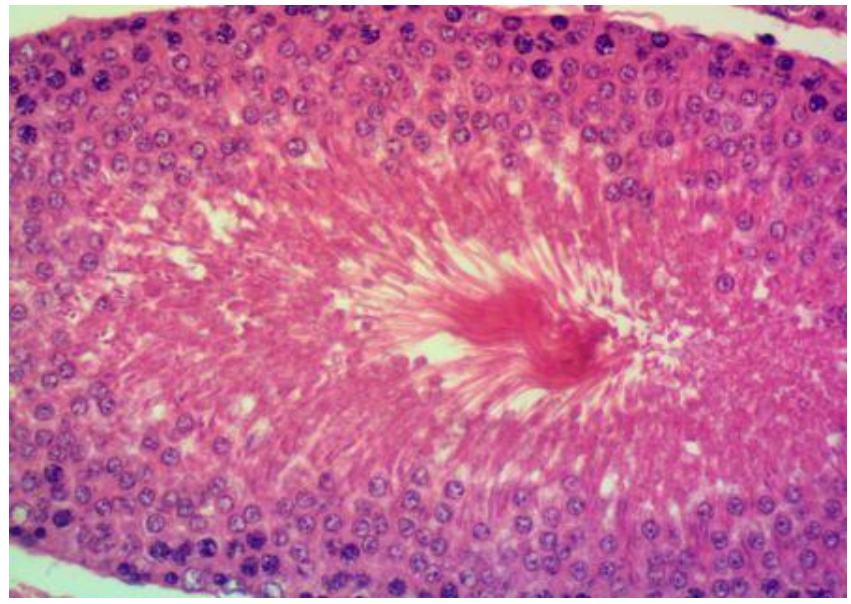

Figure 12: Control group. Testis. typical composition of seminal tubules with spermatogenesis. H\&E, 400x.

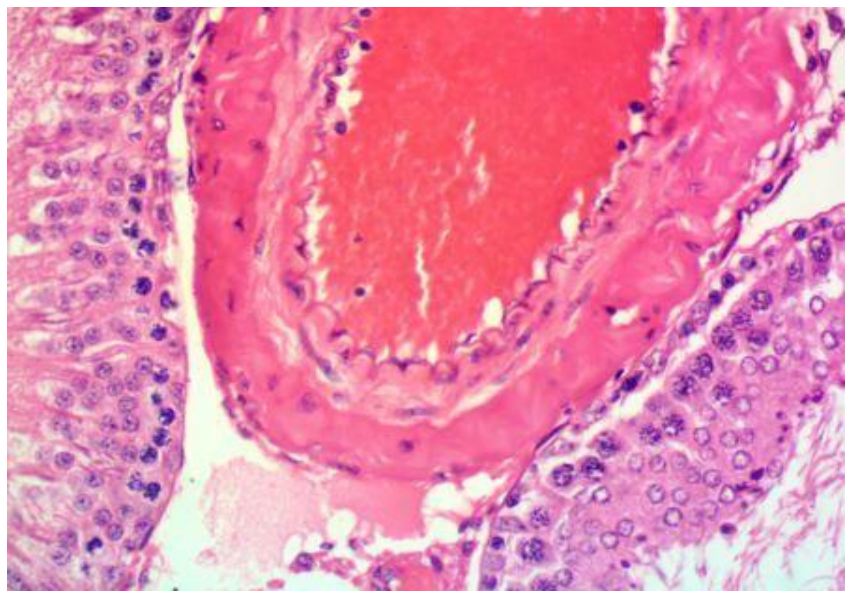

Figure 13: Control group. Testis. typical composition of seminal tubules, and Leydig cells. H\&E, 400x.

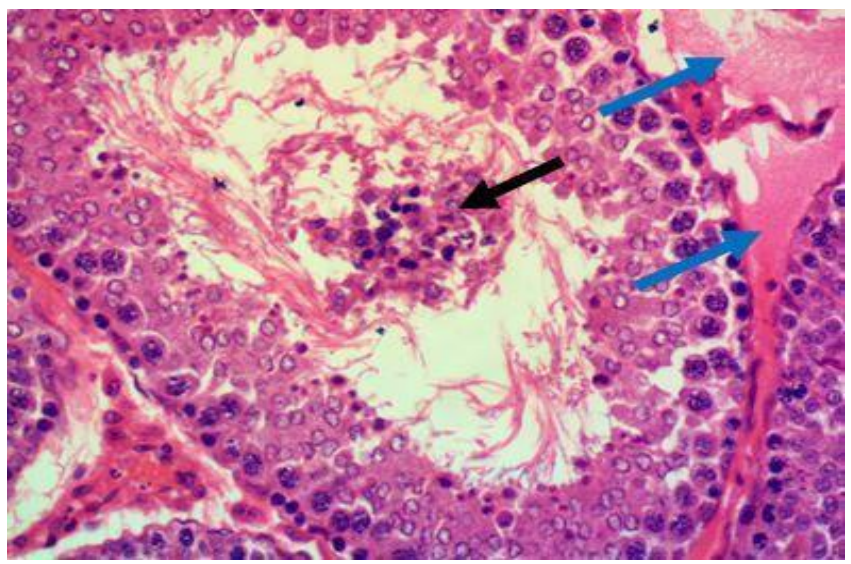

Figure 14: 150 PPM group. Testis. Showing multinucleated spermatids (arrow) in the lumen of seminal tubules with amorphous eosinophilic material in the interstitial tissue (arrow). H\&E, 400x.

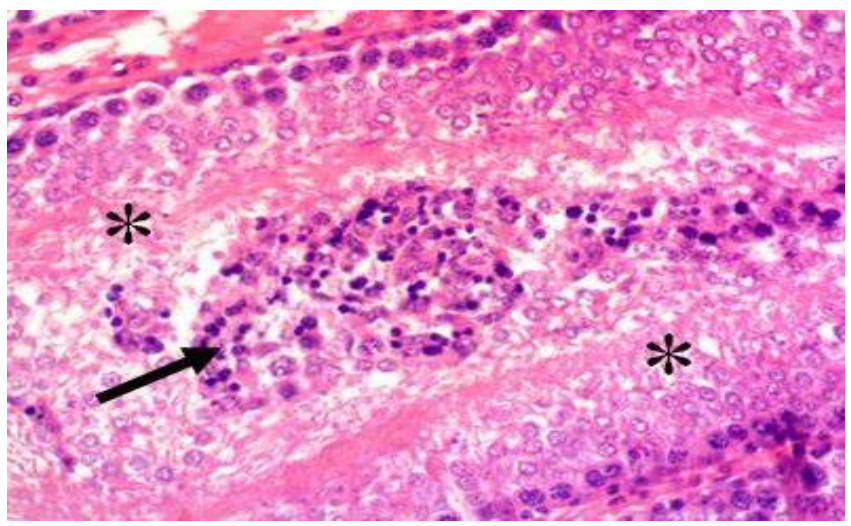

Figure 15: 150 PPM group. Testis. Showing apoptotic and sloughed spermatogonia (arrow) in the lumen of seminiferous tubules with coagulative degeneration in the spermatid cell stage (star). H\&E, 400x. 


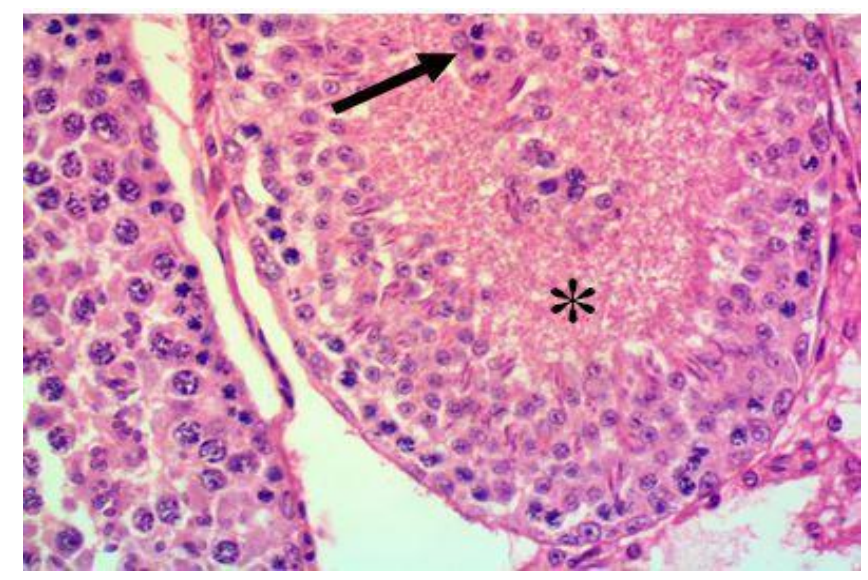

Figure 16: 300 PPM group. Testis. Showing massive coagulative necrosis in spermatid cell stage (star), which appears as cellular debris (arrow) with complete absence of spermatozoa with few apoptotic figures at periphery. H\&E, 400x.

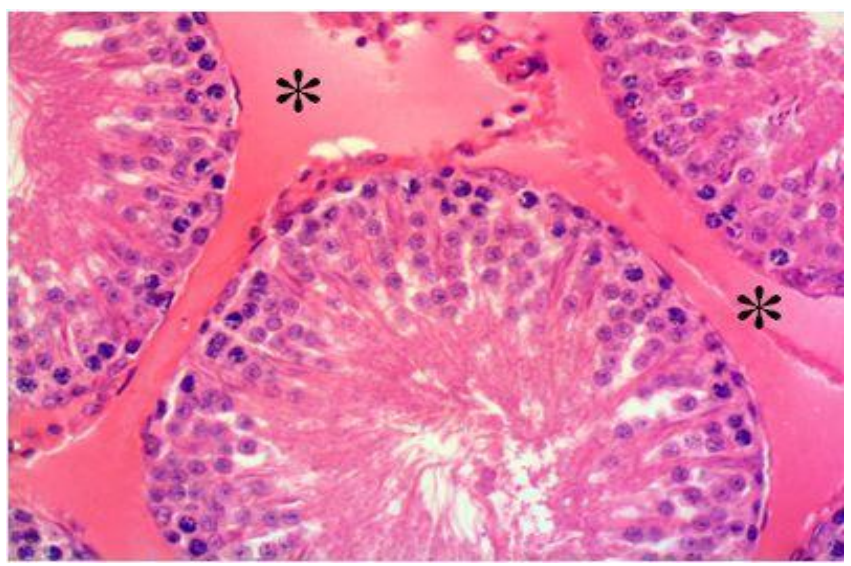

Figure 17: 300 PPM group. Testis. Showing deposition of amorphous eosinophilic material between tubules (star). $\mathrm{H} \& \mathrm{E}, 400 \mathrm{x}$.

\section{Discussion}

The current work shows a significant reduction organs weight of the $\mathrm{NaF}$ treated groups as compared to the control groups, and this may be due to adverse effects of this materials on the physiological status of animals and due to changes in the metabolism of mechanism sodium fluoride causing inhibition inactivity of some enzyme that disrupted the metabolic processes like the synthesis of protein, glycolysis, and antioxidant.

All these changes leading to a reduction in organs weights, we're in agreement with the results of the Kumar et al. (12) and contradicted with the result of the Chioca et al. (13) who mentioned that $\mathrm{NaF}$ doesn't alter the weights of organs and body weights. The ovary is an significant organ of numerous reproductive toxicants and female rats reproductive functions that exposed to $\mathrm{NaF}$ was markedly decrease and destroy, and this effects may have been caused by ovarian abnormality, and due to toxicity exposure to $\mathrm{NaF}$, the histopathological changes in the treated groups showed a decrease in the number of Graafian follicles with increase numbers of growing follicles, in addition to different stage of developing of atretic follicles and these results are in accordance with the Farooqi and Maity et al. $(14,15)$ which assign the decrease in the number of Graafian follicles to reduced number of cell, division of it, and to differentiation in germ cell through oogenesis. In rat's male genital system, testis and epididymis typical structures and the equilibrium between the secretion of estrogen and androgen are critical for maturation of sperm and formation of spermatogenesis, abnormality in function, structures, morphology of sperm not only impact the quality of semen, but also leading to infertility.

The testis produce sperm in the male genital system; the structure of testis is necessary for maintaining the spermatogenesis, exposure to fluoride could cause apparent damage in the testis by necrosis and degeneration of seminiferous tubules (16). Also, changes in the structure of the spermatogenic cell, cause the maturation and differentiation of spermatocytes (17). At the current study sodium fluoride treatment for 90 days significantly destroy the histological structures of testis through damage of seminiferous tubules, by inducing necrosis, deposition of eosinophilic material with thickening in the tunica vaginalis (15).

\section{Conclusions}

The current work results suggest that ingestion of $\mathrm{NaF}$ have adverse effects on the body and the reproductive organ weight. On the reproductive function of male and female albino rats, these effects are more pronounced with increasing dose of the sodium fluoride.

\section{Acknowledgement}

I would like to appreciate the effort of the College of Veterinary Medicine, University of Mosul, and College of Veterinary Medicine, the University of Baghdad for supporting this research.

\section{References}

1. Choubisa SL. Fluoride in drinking water and its toxicosis in tribals of Rajasthan, India. Biol Sci Med. 2012;82(2):325-30. DOI: 10.1007/s40011-012-0047-8

2. Choubisa SL. Fluoride distribution in drinking groundwater in Rajasthan, India. Curr Sci. 2018;114(09):1851. DOI: 10.18520/cs/v114/i09/1851-1857

3. Sun W, Zhang G, Tan L, Yang K, Ai H. The fluoride coated AZ31B magnesium alloy improves corrosion resistance and stimulates bone formation in rabbit model. Materials Sci Eng. 2016;63:506-11. DOI: $\underline{10.1016 / \mathrm{j} . \mathrm{msec} .2016 .03 .016}$ 
4. Bridwell RE, Carius BM, Tomich EB, Maddry JK. Interntional toxic ingestion of sodium fluoride: A case report. Cur Med Toxicol. 2019;28:23-28. DOI: 10.7759 /cureus.5025

5. Pushpalatha T, Srinivas M, Sreenivasula Reddy P. Exposure to high fluoride concentration in drinking water will affect spermatogenesis and steroidogenesis in male albino rats. Bio Metals. 2005;18(3):207-12. DOI: $10.1007 / \mathrm{s} 10534-005-0336-2$

6. Gupta R, Khan T, Agrawal D, Kachhawa J. The toxic effects of sodium fluoride on the reproductive system of male rats. Toxicol Indust Hlth. 2007;23(9):507-13. DOI: $10.1177 / 0748233708089041$

7. Zhou Y, Zhang H, He J, Chen X, Ding Y, Wang Y. Effects of sodium fluoride on reproductive function in female rats. Food Chem Toxicol. 2013;56:297-303. DOI: $\underline{10.1016 / j . f c t .2013 .02 .026}$

8. Al-Okaily BN, Ali EH. Effect of pomegranate seed oil against hepatotoxicity- induced by sodium fluoride in adult female rats (Part II). Iraqi J Vet Med. 2019;43(1):102-112. DOI: 10.30539/iraqijvm.v43i1.480

9. Qasim HO. The antagonism effect of sodium nitrate by ascorbic acid (vitamin C) on neurobehavioral of mice. Iraqi $J$ Vet Sci. 2020;34(2):241-245. DOI: 10.33899/ijvs.2019.125863.1169

10. Suvaran SK, Layuton C, Bancroft JD. Bancroft's theory and practise of histological techniques. $7^{\text {th }}$ ed. New York: Churchill Livingstone press; 2013. 70-214 p. DOI: 10.1016/b978-0-7020-4226-3.00019-6

11. Wade AL. A handbook of statistical analyses using SPSS. Boca Raton: Wiley; 2005. 36-77 p.

12. Kumar N, Sood S, Arora B, Singh M, Beena. Effect of duration of fluoride exposure on the reproductive system in male rabbits. J Hum Reprod Sci. 2010;3(3):148. DOI: 10.4103/0974-1208.74159

13. Chioca LR, Muller JC, Boareto AC, Andreatini R, Dalsenter PR. Sodium fluoride does not alter sperm production or sperm morphology in rats. Brazilian Arch Biol Technol. 2012;55(2):257-62. DOI: 10.1590/s1516-89132012000200011

14. Farooqi A. Arsenic and fluoride pollution in water and soils. Arsenic Fluoride Contaminat. 2015:1-20. DOI: 10.1007/978-81-322-2298-9 1

15. Maity PP, Jana LR, Deb B, Perveen H, Maity M, Khatun S, Chattopadhyaya $S$. Sodium fluoride-induced uterine redox imbalance and steroidogenic hazards: dose dependent response. Res Report. 2019;52;337-347. [available at]

16. Feng D, Huang H, Yang Y, Yan T, Jin Y, Cheng X. Ameliorative effects of $\mathrm{N}$-acetylcysteine on fluoride -induced oxidative stress and DNA damage in male rats testis. Mutat Res Gen Toxicol Environ. 2015;729:35-45. DOI: 10.1016/J.mrgentox.2015.09.004

17. Su K, Sun Z, Niu R, Lei Y, Cheng J, Wang J. Cell cycle arrest and gene expression profiling of testis in mice exposed to fluoride. Environ Toxicol. 2017;32(5):1558-1565. DOI: 10.1002/tox.22377

\section{التأثيرات النسجية للتسمم المزمن بفلوريد الصوديوم

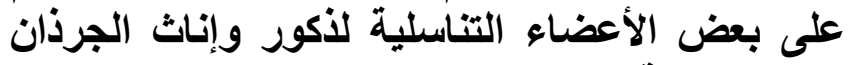

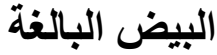

هديل باسم ذنون ا و بشرى إبراهيم القيسي

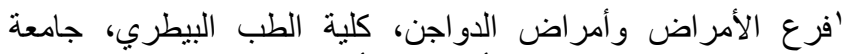

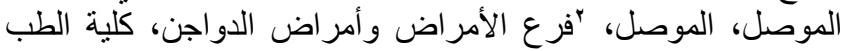

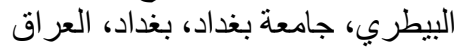

الخلاصة

هدفت الدراسة الحالية لتحديد التأثيرات المرضية للتسمم المزمن

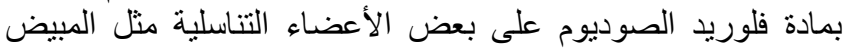

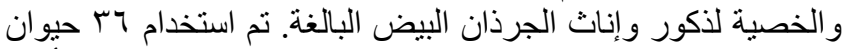

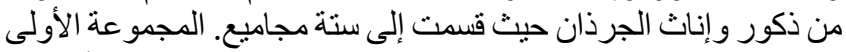

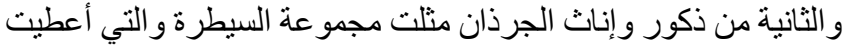

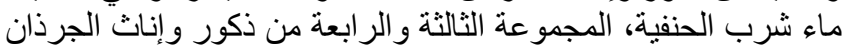

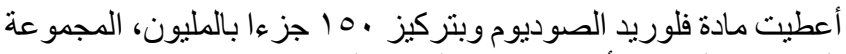

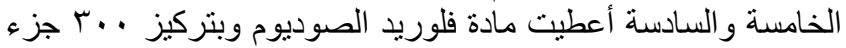

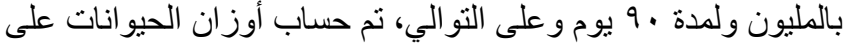

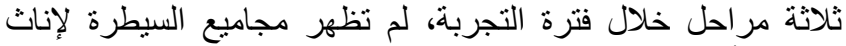

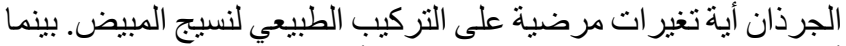

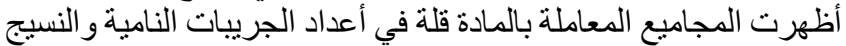

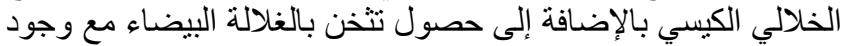

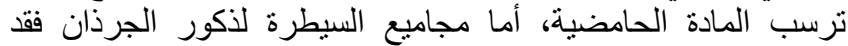

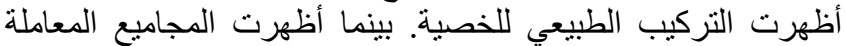

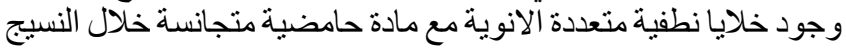

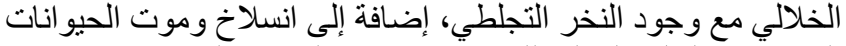

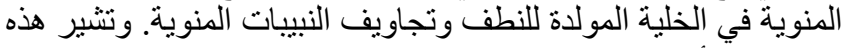

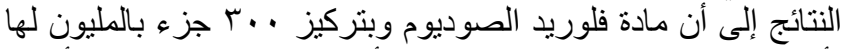

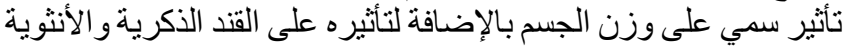
للجرذان. 